\title{
Middle Ear Cholesterol Granuloma
}

National Cancer Institute

\section{Source}

National Cancer Institute. Middle Ear Cholesterol Granuloma. NCI Thesaurus. Code C3655.

As accumulation of granulation tissue in the middle ear that results from the degeneration of blood and a chronic inflammatory response. 